factors such as age, sex and cell preparation date and differential expression of markers between groups was calculated via t-test. In parallel, PBMC B cell receptor (BCR) repertoires were investigated in 13 ACPA pos. RA patients and six age-matched healthy donors using the Illumina MiSeq platform and PCR multiplex amplicon libraries with a molecular barcode strategy to generate full variable region coverage. Sequences were filtered using PRESTO, annotated by IMGT and Change-O, finally generating 587000 unique V-regions. Total serum IgM levels were screened by sandwich ELISA in 157 population controls, 193 ACPA pos., and 50 ACPA neg. RA patients. Variable gene frequency was analyzed by Chi-square with Yates correction and serum IgM levels with Kruskal-Wallis test

Results: Several B-cell phenotypes were found to be significantly different in ACPA pos. RA compared to controls including an increase in HLA-DR across subsets, $C D 11 \mathrm{c}$ in $\lg \mathrm{A}$ memory and $\mathrm{CD} 22$ expression in clusters of mature naïve IgM positive $B$ cells. Moreover, we could see lower circulating cell counts in ACPA pos. $R A$ in $\lg$ memory $(p=0.01)$ and trends for elevation in an CXCR5/CCR6 high transitional B cell cluster $(p=0.06)$, with parallel lower number of transitional $B$ cells with lower CCR6 expression $(p=0.06)$. Notably, ACPA neg. RA generally had an intermediate phenotype between healthy controls and ACPA pos. RA. Several significant shifts in the RA BCR repertoire could be observed, including an expected higher frequency of $\mathrm{VH} \mathrm{N}$-linked glycosylation in highly mutated BCR $(p<0.0001)$. Yet, the most striking difference was a significantly higher frequency of $\mathrm{VH}$ with low somatic hypermutation (SHM) levels in RA-derived B cells ( $<5$ mutations, $p<0.000114 .7 \%$ vs $8,7)$. This was seen in all sequences, both $\operatorname{lgM}$ and class-switched, but was especially prominent in lgG1 rearrangements $(9.6 \%$ vs $18.8 \%$ low mutation, $\mathrm{p}<0.0001 \mathrm{OR}=2.2 \mathrm{Cl}: 2.0-2.35)$. In line with an $\operatorname{lgM}$ and low mutation profile in RA, we also observed that both ACPA pos. $(p<0.0001)$ and ACPA neg. $(p<0.001)$ RA patients have a significant increase in total $\operatorname{lgM}$ levels compared to controls $(1.4 \pm 0.7 ; 1.3 \pm$ $0.7 ; 1.0 \pm 0.6 \mathrm{mg} / \mathrm{ml}$, respectively).

Conclusion: Previous studies have shown that anti-citrulline autoreactivity in RA is primarily originates from memory $B$ cells and characterized by high somatic mutations and N-glycosylation sites. However, here the largest $B$ cell distortions in ACPA positive RA are observed in the naïve B cell population that have not undergone germinal center responses. These differences could reflect baseline shifts and elevated natural autoreactivity as an underlying mechanism in RA pathogenesis.

Disclosure of Interests: Yan Wang: None declared, Katy A. Lloyd: None declared, Ioannis Melas Employee of: Employed by UCB Pharma, Daniel Ramsköld: None declared, Diana Zhou: None declared, Radha Thyagarajan: None declared, Karin Lundberg: None declared, Lars Klareskog Grant/research support from: Yes, but not for the presented study., Anca Catrina Grant/research support from: Yes, but not for the presented study., Stephen Rapecki Employee of: Employed by UCB Pharma, Vivianne Malmström: None declared, Caroline Grönwall: None declared DOI: 10.1136/annrheumdis-2019-eular.7285

\section{SAT0017 COMPARISON OF IMMUNOREGULATORY WITH CONVENTIONAL DMARDS THERAPY IN PATIENTS WITH RHEUMATOID ARTHRITIS}

Qiao ling Guo ${ }^{1}$, LI Bao Chen ${ }^{1}$, LI Zhao-Hua ${ }^{1}$, Yan Yan Wang ${ }^{1}$, Xin Wang ${ }^{1}$, Chong Gao ${ }^{2}$, LI Xiaofeng ${ }^{1}$, Caihong Wang ${ }^{1} .{ }^{1}$ The second hospital of Shanxi Medical University, Rheumatology Department, Taiyuan, China; ${ }^{2}$ Department of Pathology, Brigham and Women's Hospital, Harvard Medical School, Boston, MA, USA., Department of Pathology, Massachusetts, American Samoa

Background: Rheumatoid arthritis (RA) is a chronic systemic autoimmune disease characterized by joint synovitis that ultimately leads to joint destruction and loss of function. Conventional therapy or standard medical treatment of RA involves the disease-modifying antirheumatic drugs (DMARDs). Because DMARDs act nonspecifically on the patient's immune cells, it can weaken the body's ability to fight infections. We previously reported that imbalance of effector and regulatory $T$ cells (Tregs) that should be an important cause of RA. Therefore, we developed an immunomodulatory therapy for restoring the reduced Treg cells is the main direction for the treatment of RA. [1]

Objectives: To compare the effects of new immunoregulatory therapy and conventional DMARDs therapy on disease remission and immune homeostasis in RA patients, and to investigate the efficacy of immunoregulatory therapy in the reconstruction of immune tolerance.

Methods: The study included 184 patients with RA (meeting the diagnostic classification criteria for RA revised by ACR in 1987).According to the therapeutic regimen they have received, there were assigned to the immunoregulatory (144 patients, Sirolimus capsule, $0.5 \mathrm{mg}$ twice a week and Tretinoin tablets, $10 \mathrm{mg}$ once a day, for 12 weeks) and conventional DMARDs group (40 cases, Leflunomide tablets, $10 \mathrm{mg}$ once a day for 12 weeks). Other drugs are similar between the two groups. The absolute numbers of Th17 and Treg cells in peripheral blood were measured by Flow Cytometer (FCM).

Results: 1. There was no statistically significant difference in DAS28 score $(P>0.05)$ between the two groups. 2 . In the immunomodulatory group, there were statistical differences in the number of Treg as compared with normal controls $(P<0.05)$. After immunoregulatory therapy, the absolute number of Treg cells was increased, leading to ratio of Th17/ Treg decreased (Table1, Figure1). 3. Conventional DMARDs therapy reduced, significantly the number of Treg cells $(P<0.05)$, leading to a increase in the ratio of Th17/Tregs (Table 1, Figure 2).

Conclusion: The results of this study show that the remission rates of immunomodulation group and conventional DMARDS group were $37.39 \%$ and $36.00 \%$, respectively. There was no significant difference between the two groups. But as for the effects on their immune cells, immunomodulatory therapy can increase the level of Treg cells compared with conventional DMARDs. It also shows that immunomodulatory therapy may play an important role in restoring immune tolerance in patients with RA, which may help us find new ideas for treating RA. However we need to enlarge the sample size and extend the treatment time to observe the long-term efficacy of the immunomodulatory therapy in the population.

\section{REFERENCE}

[1] Benson R A, Patakas A, Mcqueenie R, et al. Arthritis in space and time To boldly go![J]. Febs Letters, 2011, 585(23):3640-3648.
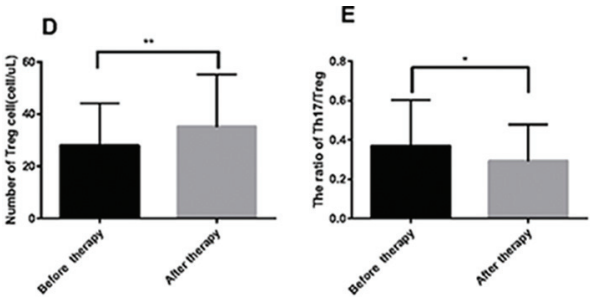

Figure 1. The number of Treg cells and the ratio of Th17/Treg before and after immunomodulatory therapy.

Table 1. The number of Th17 and Treg cell (cell/ul), ratio of Th17/Treg in immunomodulatory therapy and Traditional DMARDs therapy.

\begin{tabular}{|c|c|c|c|c|c|c|}
\hline \multirow{2}{*}{$\begin{array}{l}\text { Immune } \\
\text { Cells }\end{array}$} & \multicolumn{2}{|c|}{ Immunomodulatory $\mathrm{n}=144$} & \multicolumn{2}{|c|}{ Traditional DMARDs $\mathrm{n}=40$} & \multirow{2}{*}{$\begin{array}{c}P \text { value } A \text { vs } \\
B\end{array}$} & \multirow{2}{*}{$\begin{array}{c}P \text { value } C \text { vs } \\
D\end{array}$} \\
\hline & $\begin{array}{l}\text { Before therapy } \\
\text { (A) }\end{array}$ & $\begin{array}{l}\text { After therapy } \\
\text { (B) }\end{array}$ & $\begin{array}{l}\text { Before therapy } \\
\text { (C) }\end{array}$ & $\begin{array}{l}\text { After therapy } \\
\text { (D) }\end{array}$ & & \\
\hline Th17 & $\begin{array}{c}8.6453 \\
(4.673,11.000)\end{array}$ & $\begin{array}{c}9.2359 \\
(4.440,12.570)\end{array}$ & $\begin{array}{c}7.4693 \\
(4.300,10.850)\end{array}$ & $\begin{array}{c}9.8622 \\
(4.045,8.100)\end{array}$ & 0.086 & 0.512 \\
\hline Treg & $\begin{array}{c}27.9202 \\
(15.900,36.270)\end{array}$ & $\begin{array}{c}31.9208 \\
(22.90,39.7775)\end{array}$ & $\begin{array}{c}38.6240 \\
(31.190,43.120)\end{array}$ & $\begin{array}{c}30.2330 \\
(24.150,37.380)\end{array}$ & 0.021 & 0.001 \\
\hline Th17/Treg & $\begin{array}{c}0.3669 \\
(0.199,0.490)\end{array}$ & $\begin{array}{c}0.2907 \\
(0.172,0.341)\end{array}$ & $\begin{array}{c}0.2343 \\
(0.127,0.347)\end{array}$ & $\begin{array}{c}0.3581 \\
(0.202,0.515)\end{array}$ & 0.020 & 0.024 \\
\hline
\end{tabular}



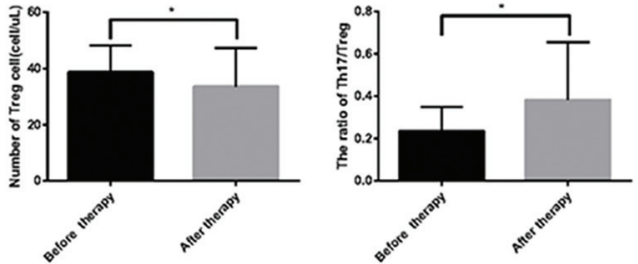

Figure 2. The number of Treg cells and the ratio of Th17/Treg before and after conventional DMARDs therapy.

Disclosure of Interests: None declared

DOI: 10.1136/annrheumdis-2019-eular.6389

\section{SAT0018 THE STUDY OF CD4+T CELL SUBSETS IN RECURRENT POLYCHONDRITIS}

Fang Yuan $\mathrm{Hu}^{1}$, Ning Yan ${ }^{1}$, Jie Liang ${ }^{1}$, Rui Su${ }^{1}$, Chong Gao ${ }^{2}$, LI Xiao-Feng ${ }^{1}$, Caihong Wang $1 .{ }^{1}$ The Second Hospital of Shanxi Medical Univerity, Taiyuan, China; ${ }^{2}$ Department of Pathology, Brigham and Women's Hospital, Harvard Medical School, Boston, MA, United States of America

Background: Relapsing polychondritis (RP) is an rare inflammatory disease of unknown causes, characterized by recurrent inflammation in cartilaginous tissues of the whole body ${ }^{[1]}$. The histologic features of the chondritis include loss of basophilic staining of the cartilage matrix, perichondrial inflammation, cartilage destruction with replacement by fibrous tissue, and perivascular cellular infiltration with plasma cells and lymphocytes. Additional clinical features of the disease include ocular inflammation, vasculitis, audiovestibular dysfunction, myocarditis, cardiac valvular insufficiency, and nonerosive inflammatory arthritis. Many studies have shown that the imbalance of helper $T$ cell 17(Th17) and regulatory $T$ cell (Treg) is involved in the pathogenesis of autoimmune diseases such as SLE and RA. But little is known about the roles of peripheral immune cell subsets peripheral in RP patients. Up to now, just few studies focus on this issue.

Objectives: We aimed to analyse the distribution and phenotype of CD4 $+\mathrm{T}$ cell subsets in the peripheral blood of patients with RP.

Methods: The proportion and absolute counts of circulating immune cells were assessed in 14 patients diagnosed as RP and 14 healthy controls. $\mathrm{CD} 4+\mathrm{T}$ cell subsets were also analysed in 9 untreated RP patients and 9 healthy volunteers by flow cytometry. All statistical analyses were performed with SPSS v. 22.0. Continuous variables were reported as median. For all study variables, comparison among controls and RP subjects was based on the non-parametric Wilcoxon Mann-Whitney exact test. For all analyses, we used two-sided tests, with p-values $<0.05$ denoting statistical significance.

Results: Proportion and absolute counts of Treg cells were significantly reduced in RP patients in comparison with controls (proportion, $3.61 \%$ vs. $5.24 \%, p<0.001$; absolute counts, $27.36 / \mu l$ vs. $46.56 / \mu l, p<0.001)$. But there were no significant difference between the percentage and number of Th17, Th1 or Th2 cells in patients with RP and healthy controls. Thus, the ratio of Th17/Treg increased in RP patients $(0.25$ vs. $0.14, p<0.001)$, as did the ratio of Th2/Treg (0.28 vs. $0.22, p<0.001)$ and Th1/Treg( 2.75 vs. 1.92, $\mathrm{p}=0.019$ )(Figue 1). Similarly, the proportion and absolute counts of Treg cells in untreated RP patients were significantly lower than that in healthy controls (proportion, $3.78 \%$ vs. $5.66 \%, \quad \mathrm{p}=0.008$; absolute counts, $32.24 / \mu \mathrm{l}$ vs. $50.76 / \mu \mathrm{l}, \mathrm{p}<0.001)$. And the ratio of Th17/Treg slso increased in untreated RP patients $(0.25$ vs. $0.15, p=0.003)$, as did the ratio of Th1/Treg (2.35 vs. $1.88, \mathrm{p}=0.014)$ (Figue 2).

Conclusion: Our data suggested that the immune-inflammation in RP patients may be related to the depletion of Treg cells and the imbalance of Th17 or Th1 or Th2 and Treg cells.Reduction of peripheral Treg cells may exacerbate the disease progression by not being inhibited Th cells.

\section{REFERENCE}

[1] Kingdon J, Roscamp J, Sangle S, et al. Relapsing polychondritis: a clinical review for rheumatologists[J]. Rheumatology, 2017, 57(9): 1525-1532.

Acknowledgement: Rheumatology and laboratory staff in the Second Hospital of Shanxi Medical University

Disclosure of Interests: None declared

DOI: 10.1136/annrheumdis-2019-eular.1250
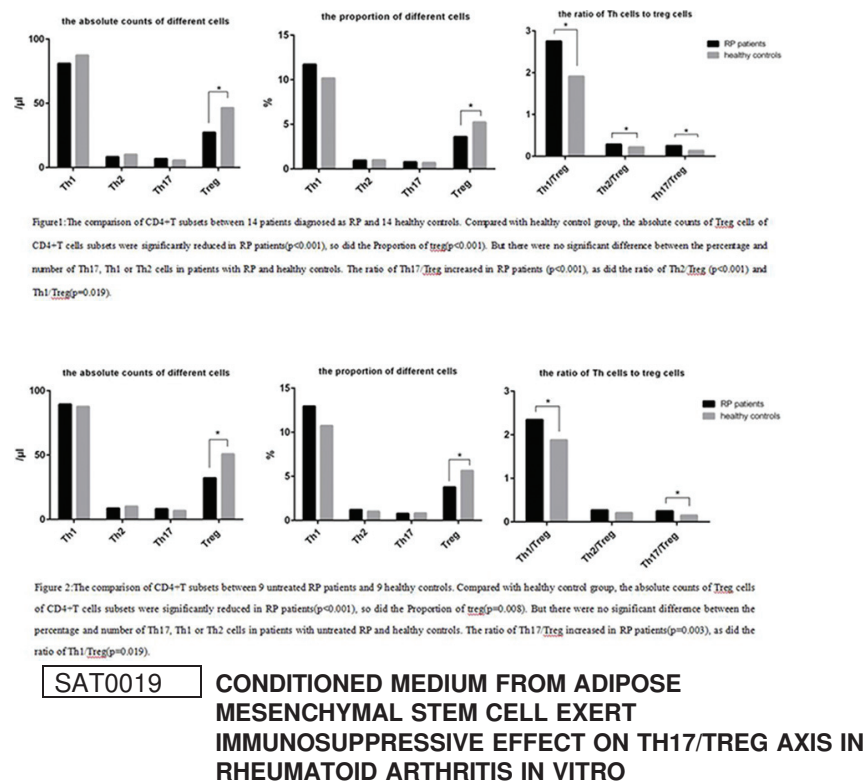

Georgi Vasilev $^{1}$, Mariana Ivanova Goycheva ${ }^{2}$, Ekaterina Ivanova-Todorova ${ }^{1}$, Kalina Tumangelova-Yuzeir ${ }^{1}$, Ekaterina Kurteva ${ }^{1}$, Rumen Stoilov' ${ }^{2}$,

Dobroslav Kyurkchiev'. ${ }^{1}$ Medical Faculty, Medical University, University Hospital "St. Ivan Rilski", Laboratory of Clinical Immunology, Sofia, Bulgaria; ${ }^{2}$ Medical Faculty, Medical University, University Hospital "St. Ivan Rilski", Clinic of Rheumatology, Sofia, Bulgaria

Background: Emerging data have demonstrated that mesenchymal stem cells (MSC) are well endowed with a broad repertoire of immunosuppressive tools and they could modulate the immune response on several levels via production of a plethora of soluble factors and contact-dependent mechanisms. For these reasons, mesenchymal stem cells-based protocols were spotlighted as promising multiple-hit treatment candidates for therapeutic intervention in a multitude of autoimmune diseases and debilitating conditions such as rheumatoid arthritis (RA).

Objectives: In line with aforementioned and taking in mind the current shift in Th1/Th2 paradigm suggesting a key role of Th17/Treg axis dysregulations in RA pathogenesis, we aimed to appraise the immunoregulatory effects of secretory factors produced by adipose-derived MSC (ATMSC) on Th17 and Tregs subsets and also pro-inflammatory cytokines production in patients with RA.

Methods: The study encompasses 17 patients matching the ACR/EULAR 2010 criteria for RA. AT-MSC were isolated and cultured according to well-established protocols. Peripheral blood mononuclear cells (PBMCs) isolated from RA patients' samples were cultured in AT-MSC conditioned media and in control media. Flow cytometry was used for detection of Th17 and Treg markers (of CD3, CD4, CD161, CD196 and CD25 and intracellular expression of FoxP3). ELISA was performed for testing the cytokines produced by PBMC (TGF- $\beta 1$, TNF- $\alpha$, IL-17A, IL-21).

Results: We found significant elevation in percentage of $\mathrm{CD} 4^{+} \mathrm{CD} 25^{+} \mathrm{FoxP}^{+}$Treg cell in the pool of PBMC cultured with AT-MSC as opposed to control medium, $4.22 \pm 2 \%$ (mean \pm SD) vs. $6.04 \pm$ $3.6 \%(p=0.001)$. Paired sample analysis of Th17 cells percentage values from all $\mathrm{CD}^{+}$in PBMC cultured with control media (mean $\pm \mathrm{SD}$ ) $10.13 \pm 3.88 \%$ in contrast to Th17 percentage in PBMC cultured with AT-MSC supernatants $8.98 \pm 3.58 \%$ showed significant decrease in Th17 numbers $(p=0.02)$ under the influence of AT-MSC secretory factors. Cultivation of RA patient's PBMCs with AT-MSC supernatants led to significant up-regulation of TGF- $\beta 1$ levels, (median [IQR]) $8.318 \mathrm{ng} / \mathrm{ml}(6.327$ - $11.686 \mathrm{ng} / \mathrm{ml})$ vs. $6.227 \mathrm{ng} / \mathrm{ml} ;(1.681-10.148 \mathrm{ng} / \mathrm{ml})(p=0.013)$ and decrease in levels of TNF- $\alpha, \mathrm{IL}-17 \mathrm{~A}$, and IL-21 respectively: $5 \mathrm{pg} / \mathrm{ml}$ $(1.75-11.65 \mathrm{pg} / \mathrm{ml})$ vs. $1 \mathrm{pg} / \mathrm{ml}(0.7-1.9 \mathrm{pg} / \mathrm{ml})(\mathrm{p}=0.001) ; 4.2 \mathrm{pg} /$ $\mathrm{ml}(3.1-6.1 \mathrm{pg} / \mathrm{ml})$ vs. $2.3 \mathrm{pg} / \mathrm{ml}(0.75-5.42 \mathrm{pg} / \mathrm{ml})(\mathrm{p}=0.017) ; 75.1$ $\pm 35.95 \mathrm{pg} / \mathrm{ml}$ vs. $52.09 \pm 30.8 \mathrm{pg} / \mathrm{ml}(\mathrm{p}=0.022)$. The reduction in IL17 levels positively correlated with the decrease of TNF- $\alpha(r=0.921, p$ $=0.001$.

Conclusion: Our study unambiguously demonstrated that secretory factors produced by AT-MSC exert an immunoregulatory effect on Th17 and Treg cells and also could inhibit major effector cytokine pathways: TNF- $\alpha$, $\mathrm{IL}-17, \mathrm{IL}-21$ production in RA in vitro. The study of mechanisms of immunoregulation induced by MSCs provide us better insight into the pathogenesis of rheumatoid arthritis and could be a potential therapeutic approach. 